University of Nebraska - Lincoln

DigitalCommons@University of Nebraska - Lincoln

2003

An Analysis of the Secondary Structure of the Mitochondrial Large Subunit rRNA Gene (16S) in Spiders and Its Implications for Phylogenetic Reconstruction

\author{
Stacey DeWitt Smith \\ University of Nebraska - Lincoln, ssmith19@unl.edu \\ Jason E. Bond \\ East Carolina University
}

Follow this and additional works at: https://digitalcommons.unl.edu/bioscifacpub

Part of the Life Sciences Commons

Smith, Stacey DeWitt and Bond, Jason E., "An Analysis of the Secondary Structure of the Mitochondrial Large Subunit rRNA Gene (16S) in Spiders and Its Implications for Phylogenetic Reconstruction" (2003). Faculty Publications in the Biological Sciences. 111.

https://digitalcommons.unl.edu/bioscifacpub/111

This Article is brought to you for free and open access by the Papers in the Biological Sciences at DigitalCommons@University of Nebraska - Lincoln. It has been accepted for inclusion in Faculty Publications in the Biological Sciences by an authorized administrator of DigitalCommons@University of Nebraska - Lincoln. 


\title{
AN ANALYSIS OF THE SECONDARY STRUCTURE OF THE MITOCHONDRIAL LARGE SUBUNIT RRNA GENE (16S) IN SPIDERS AND ITS IMPLICATIONS FOR PHYLOGENETIC RECONSTRUCTION
}

\author{
Stacey D. Smith ${ }^{1}$ : Department of Biology, Virginia Polytechnic Institute and State \\ University, Blacksburg, Virginia 24061 USA \\ Jason E. Bond: East Carolina University, Department of Biology, Howell Science \\ Complex, Greenville, North Carolina 27858 USA
}

\begin{abstract}
We investigated the pattern of molecular variation with respect to secondary structure in the 16S ribosomal RNA gene and its phylogenetic implications for arachnids with a focus on spiders. Based on a model by Gutell et al. (1996), secondary structures were proposed for the 3' half of $16 \mathrm{~S}$ in the mygalomorph spider Aptostichus atomarius. Models were also constructed for a hypervariable length of the $16 \mathrm{~S}$ in three other arachnids, which revealed a trend of stem and loop reduction in more advanced arachnids. Using a simple statistical approach to compare functional regions, we found that internal and external loops are more variable than stems or connection regions. Down-weighting or excluding regions which code for the more variable loops improved tree topologies by restoring the monophyly of the genus Aptostichus, a group supported by combined 16S, COI, and morphological data in other analyses. This study demonstrated the utility of considering secondary structure for DNA sequence alignment and phylogenetic reconstruction in spiders.
\end{abstract}

Keywords: Secondary structure, 16S rRNA gene, Aptostichus, phylogenetic utility

The most important aspect of any molecular phylogenetic study is, unequivocally, gene choice. Choosing a gene that strikes the appropriate balance between molecular conservation and variability is essential to the success of phylogenetic reconstruction. Without question the functional role of a gene and its rate of evolution are tightly coupled although within genes, this relationship is variable because regions of a single gene can evolve at different rates. This tight relationship between rate of nucleotide substitution and gene component "form and function" results in a single gene being useful at different, sometimes quite disparate phylogenetic levels. Such multilevel phylogenetic utility, strongly tied to gene function (i.e., the functional secondary structure) is particularly true for the mitochondrial 16S rRNA gene in arthropods (Flook \& Rowell 1995), the gene of focus for this paper.

\footnotetext{
${ }^{1}$ Current address: Stacey D. Smith, Department of Botany, 430 Lincoln Dr., University of Wisconsin, Madison, WI 53706-1481. E-mail: sdsmith4@ wisc.edu
}

The 16S rRNA gene, which encodes the mitochondrial large ribosomal subunit $(\mathrm{mt}$ LSU) in animals, has been employed extensively to explore phylogenetic relationships in arthropods at most phylogenetic levels [e.g., ordinal (e.g., Flook \& Rowell 1995), familial level (e.g., Black \& Piesman 1994) and the genus level and below (e.g., DeSalle et al. 1992; Bond et al. 2001)]. The wide range in utility of $16 \mathrm{~S}$ at various taxonomic levels suggests that the differential rates of molecular evolution within $16 \mathrm{~S}$, due to varying functional constraints, greatly affect its phylogenetic utility. Thus, understanding the functional roles of different portions of the gene through secondary structure modeling should lead to a more robust use of $16 \mathrm{~S}$ in phylogenetic studies.

The main focus of this paper is the secondary structure of $16 \mathrm{~S}$ in spiders and other arachnids. One of the first models of $16 \mathrm{~S} \mathrm{sec-}$ ondary structure in arthropods was created by Clary \& Wolstenholme (1985) using the Drosophila yakuba sequence. Subsequent models by Gutell and colleagues (Gutell \& Fox 1988; 
Table 1.-Spider taxa sampled.

\begin{tabular}{|c|c|c|c|}
\hline $\begin{array}{l}\text { Higher level } \\
\text { classification }\end{array}$ & Species & Origin & $\begin{array}{c}\text { Reference/GenBank } \\
\text { accession \# }\end{array}$ \\
\hline \multicolumn{4}{|l|}{ Mesothelae } \\
\hline Liphistiidae & Heptathela nishihirai Haupt 1979 & Japan & Huber et al. 1993 \\
\hline \multicolumn{4}{|l|}{ Opisthothelae } \\
\hline \multicolumn{4}{|l|}{ Araneomorphae } \\
\hline Clubionidae & Clubiona pallidula (Clerck 1757) & Austria & Huber et al. 1993 \\
\hline Ctenidae & $\begin{array}{l}\text { Cupiennius coccineus F. Pickard-Cam- } \\
\quad \text { bridge } 1901\end{array}$ & Costa Rica & Huber et al. 1993 \\
\hline Ctenidae & Cupiennius getazi Simon 1891 & Costa Rica & Huber et al. 1993 \\
\hline Ctenidae & Cupiennius salei (Keyserling 1877) & Mexico & Huber et al. 1993 \\
\hline Ctenidae & $\begin{array}{l}\text { Phoneutria boliviensis (F.O. Pickard- } \\
\text { Cambridge 1897) }\end{array}$ & Costa Rica & Huber et al. 1993 \\
\hline Lycosidae & Pardosa agrestis (Westring 1861) & Austria & Huber et al. 1993 \\
\hline Pisauridae & Dolomedes fimbriatus (Clerck 1757) & Austria & Huber et al. 1993 \\
\hline Pisauridae & Pisaura mirabilis (Clerck 1757) & Austria & Huber et al. 1993 \\
\hline \multicolumn{4}{|l|}{ Mygalomorphae } \\
\hline Antrodiaetidae & Antrodiaetus unicolor (Hentz 1841) & Virginia & AY241258 \\
\hline Cyrtaucheniidae & Aptostichus atomarius Simon 1891 & California & AY241254 \\
\hline Cyrtaucheniidae & $\begin{array}{l}\text { Aptostichus simus Chamberlin } 1917 \text { (3 } \\
\text { populations sampled, Bond et al. } \\
\text { 2001) }\end{array}$ & California & $\begin{array}{l}\text { AF307969, } \\
\text { AF307964, } \\
\text { AF307960 }\end{array}$ \\
\hline Cyrtaucheniidae & Aptostichus sp. & California & AY241255 \\
\hline Cyrtaucheniidae & $\begin{array}{l}\text { Entychides arizonicus Gertsch \& Wal- } \\
\text { lace } 1936\end{array}$ & Arizona & AY241257 \\
\hline Cyrtaucheniidae & $\begin{array}{l}\text { Promyrmekiaphila gertschi Schenkel } \\
1950\end{array}$ & California & AY241256 \\
\hline
\end{tabular}

Gutell et al. 1993) were based on extensive surveys of sequences as well as studies of positional covariance; these are thus considered to be more accurate and have been used in recent studies modeling secondary structure in arthropods (e.g. Buckley et al. 2000). Existing secondary structure models of $16 \mathrm{~S}$ in arachnids are limited to a tick (Black \& Piesman 1994), which used the Clary \& Wolstenholme (1985) model and two spider species of the infraorder Araneomorphae (Huber et al. 1993; Masta 2000), which used the Gutell model (Gutell \& Fox 1988). To obtain a more complete picture of arachnid 16S secondary structure, this study will examine the secondary structure of the other "primitive" infraorder of spiders, the Mygalomorphae (Coddington \& Levi 1991), and, to a lesser extent, primitive liphistiid spiders, Acari (ticks) and Scorpiones using the Gutell model. Spider taxa from disparate groups were examined as part of a concerted effort to sample across all of the major clades. Table 1 summarizes the taxa used in this analysis, the classificatory placement of these taxa, and the source of their sequences. Decisions regarding taxon choice within the Mygalomorphae reflect an attempt to examine taxa across a number of phylogenetic levels within this clade.

The major objectives of this study are to: 1) construct a secondary structure model for mygalomorph spiders using the preferred $\mathrm{Gu}$ tell model, 2) examine trends in secondary structure evolution in spiders and other arachnids, 3) analyze the pattern of molecular variation with respect to structure in mygalomorphs and araneomorphs, and 4) assess the effects that differential weighting of molecular characters based on secondary structure has on phylogeny reconstruction in spiders. This is the first study of arachnids to examine the rates of variation in 16S rRNA relative to secondary structure in a rigorous statistical manner and to analyze secondary structure trends across the class. It is also the first to consider the implications of secondary structure in se- 
quence alignment and phylogenetic reconstruction in arachnids.

\section{METHODS}

DNA extractions. - Total genomic DNA was extracted from leg tissue using a Puregene DNA extraction kit, which comprises a lysis step in which ground tissue is incubated in Tris-EDTA buffer with SDS and Proteinase $\mathrm{K}$ for three hours, a protein precipitation step using potassium acetate, followed by DNA precipitation in isopropanol, and a 70\% ethanol wash. DNA was resuspended in TrisEDTA buffer and diluted 1:100 for subsequent reactions.

Mitochondrial gene PCR and sequencing.- The polymerase chain reaction (PCR) was used to amplify the 16S rRNA gene with the $16 \mathrm{~S}$ universal primers $16 \mathrm{sar}-5^{\prime}$ ( $5^{\prime}$ CGCCTGTTTATCAAAAACAT- $\left.3^{\prime}\right)$ and $16 \mathrm{sbr}-3^{\prime} \quad$ (5'-CCGGTCTGAACTCAGATCACGT-3') (Hillis et al. 1996). The primers 16 sar-5' and $16 \mathrm{sbr}-3^{\prime}$ correspond to Drosophila melanogaster mitochondrial genome positions 13398 and 12887 respectively. Standard PCR reactions were carried out in $50 \mu 1$ volumes and run for 35 cycles, each consisting of a $30 \mathrm{sec}$ denaturation at $95{ }^{\circ} \mathrm{C}, 30 \mathrm{sec}$ annealing at $50^{\circ} \mathrm{C}$ and $45 \mathrm{sec}(+3 \mathrm{sec} / \mathrm{cycle})$ extension at $72^{\circ} \mathrm{C}$, with an initial denaturation step of $95^{\circ} \mathrm{C}$ for $2.5 \mathrm{~min}$ and a final extension step of $72^{\circ} \mathrm{C}$ for $10 \mathrm{~min}$. Amplification products were electrophoresed on a $0.8 \%$ agarose gel, excised from the gel and purified using Qiagen QIAquick gel extraction columns. Purified products were sequenced from both directions with an ABI PRISM 377 and 310 automated sequencers using the ABI PRISM Dye Terminator Cycle Sequencing Ready Reaction Kit with Amp1iTaq DNA Polymerase, FS.

Secondary Structure.-Mygalomorph 16S sequences generated for six taxa were crudely aligned (alignment of stem regions was improved by eye once the secondary structure was obtained) with sequences from eight araneomorph taxa (Table 1) and Drosophila melanogaster using ClustalX (Higgins et al. 1996). The 16S rRNA secondary structure was predicted for the mygalomorph Aptostichus atomarius Simon 1891 (Fig. 1) by comparison with sequences and models from Drosophila yakuba (Gutell et al. 1993) and an araneomorph (Huber et al. 1993). We assumed that the location of stems and loops would be very similar because the LSU rRNA secondary structure has been found to be widely conserved (Buckley et al. 2000; Masta 2000). The A. atomarius sequence was chosen because it had the highest similarity to Drosophila, facilitating comparison.

To examine evolution of secondary structure in arachnids, models were also created for a hypervariable portion of the molecule (Fig. 1) in distantly related arachnid taxa: the tick Ornithodoros moubata (Murray 1877) (Black \& Piesman 1994), the scorpion Vaejovis carolianus (Beauvois 1805) and the mesothele Heptathela nishihirai Haupt 1979 (Huber et al. 1993) (Fig. 2). All structures were drawn

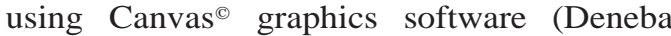
Systems Inc.).

Analysis of variability with respect to secondary structure.-Each nucleotide position was assigned a single letter designating its structural function $(\mathrm{S}=$ stem, $\mathrm{I}=$ internal loop, $\mathrm{L}=$ external loop, $\mathrm{C}=$ connecting region) and was coded as variable (1) or invariable (0). In this study, stems refer to a series of bonded nucleotides. Internal loops are those unbonded nucleotides, which occur within a stem; external loops occur at the end of stems. Connecting regions link stems.

Variation was analyzed separately for the two spider infraorders, Mygalomorphae and Araneomorphae. For each structural category, variability was calculated by dividing the number of variable positions by the total number of positions. Statistical analyses were performed using SAS (SAS Statistical Systems).

To compare the pattern of variation across structural regions to random variation within the molecule, the percent variability of random blocks within the sequence was compared to the percent of actual variability within structural units ( $\mathrm{S}, \mathrm{I}, \mathrm{L}, \mathrm{C})$. A simple random number generator program written for Mathematica (Wolfram 1996) produced nucleotide blocks in lengths of 5 or 13 consecutive numbers between 1 and 503 base pairs. The block size corresponds to the maximum and minimum average sizes of the structural regions, and the random numbers corresponded to positions along the molecule. The mean variability in the random blocks provided the expected values for a Chi-Squared Test to determine if the pattern of variability was distinct from the random model. 


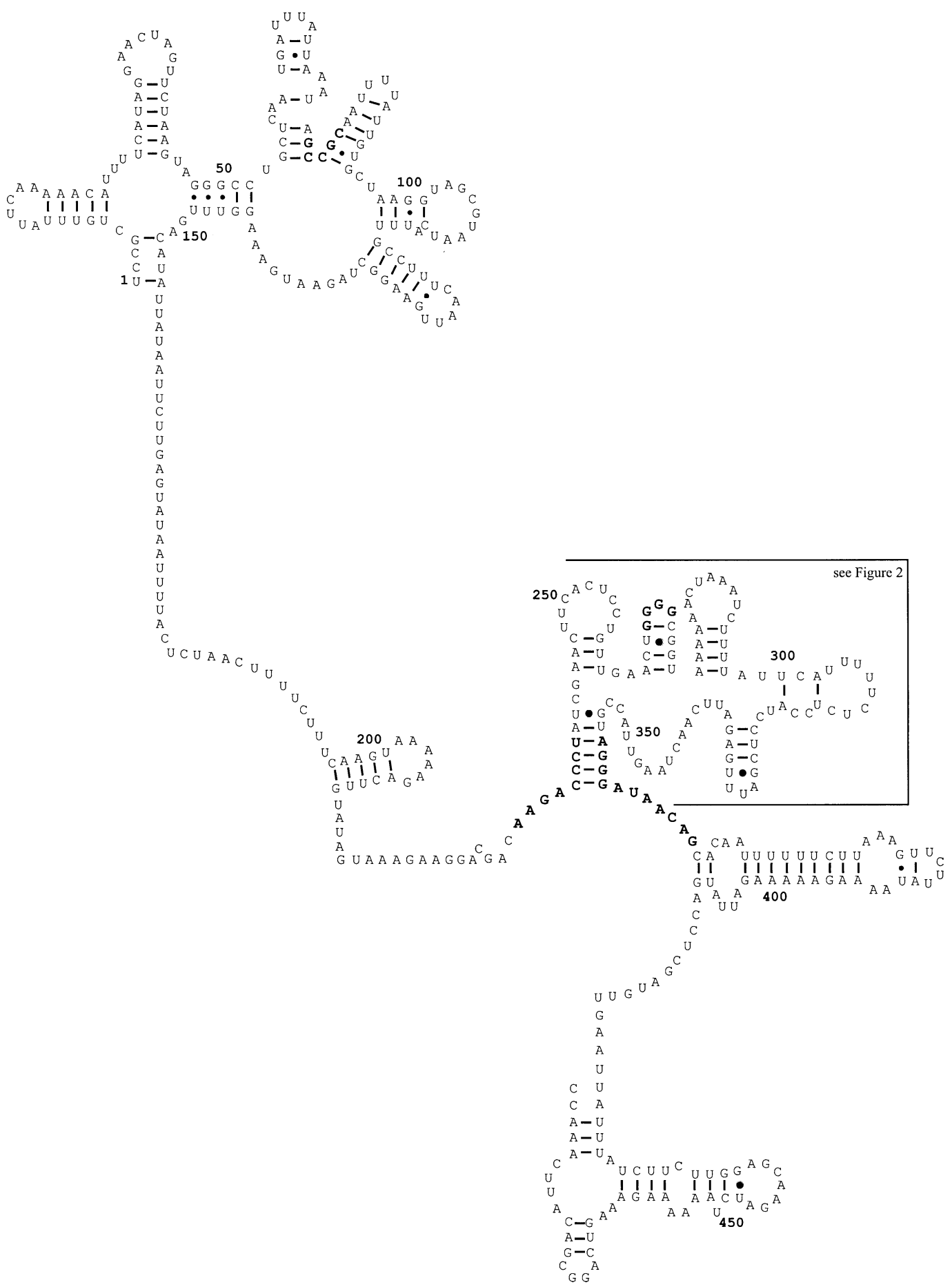

Figure 1.-Proposed secondary structure model for the $3^{\prime}$ half of $16 \mathrm{~S}$ of the mygalomorph species Aptostichus atomarius based on the Gutell et al. model (1993). Highly conserved regions indicated by bold-lettered nucleotides. Dashes represent Watson-Crick bonds; circles are U-G bonds. The hypervariable area examined in the study and modeled in Figure 3 is corresponds to nucleotide positions 237-359. 


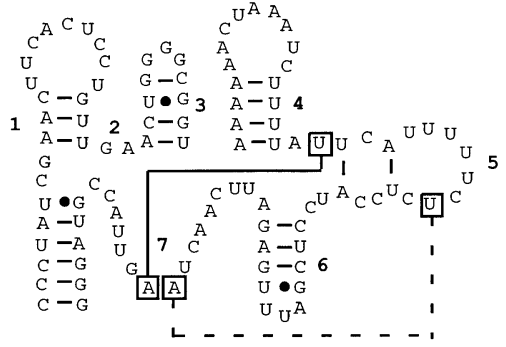

(A) Aptostichus atomarius

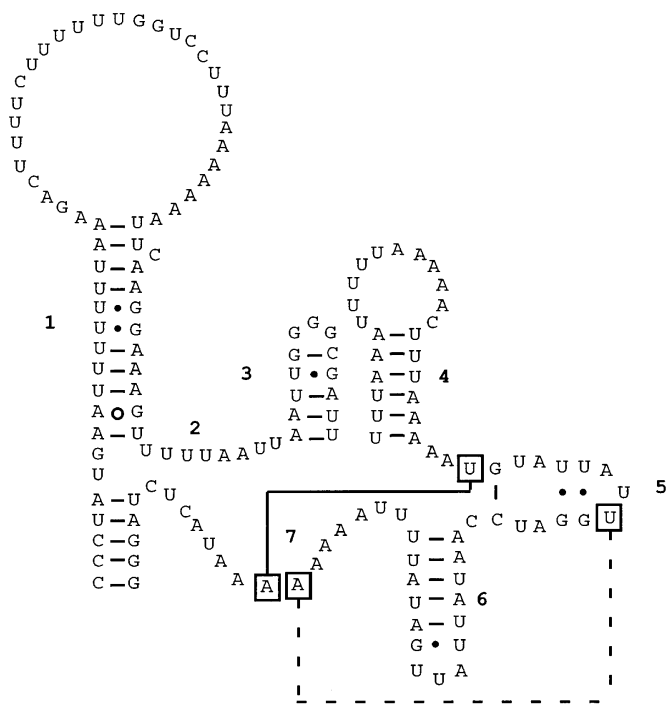

(C) Ornithodoros moubata

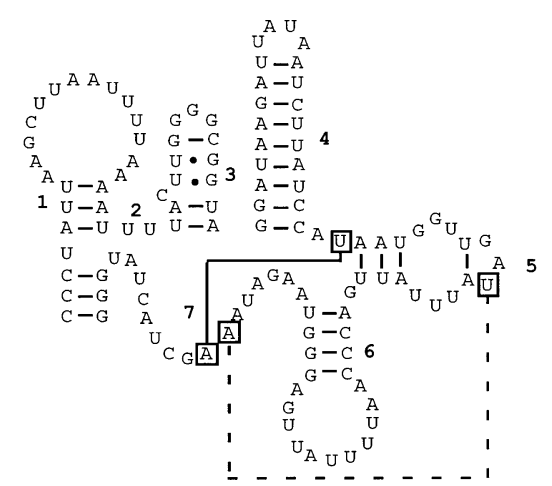

(B) Ryuthela nishihirai

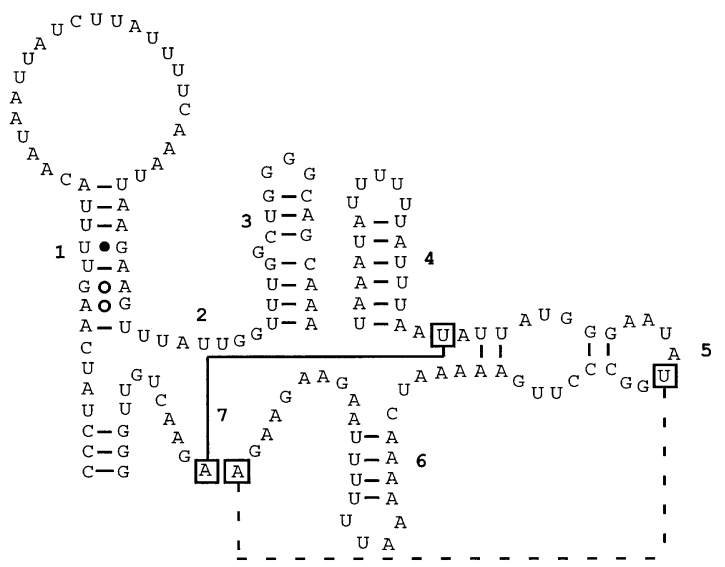

(D) Vaejovis carolianus

Figure 2.-Proposed secondary structures of a hypervariable region of $16 \mathrm{~S}$ based on Gutell et al. model (1993) for 4 Arachnid taxa. Solid lines indicate tertiary interaction with strong comparative data and dashed lines indicate those with less support (Gutell 1996). (a) Aptostichus atomarius (Mygalomorphae) (b) Ryuthela nishihirai (Mesothelae) (c) tick Ornithodoros moubata (d) scorpion Vaejovis carolianus.

Phylogenetic analysis.-_Phylogenetic analyses were performed using PAUP* version 4.0b2a (Swofford 1999) run on a Power Macintosh 6500/275. The phylogenetic signal in the data set was evaluated using the $\mathrm{g}_{1}$ statistic (Hillis \& Huelsenbeck 1992) based on 100,000 random trees generated in PAUP*. All characters were treated as reversible, unordered, and all characters were initially weighted equally. Unambiguous gaps were scored as binary characters. These binary scorings were retained and the individual nucleotide positions from which they were scored were excluded from the analysis. Oth- erwise, gaps were treated as missing characters.

Heuristic searches were performed using random addition stepwise (1000 replicates) of taxa followed by TBR (tree bisection-reconnection) branch swapping. Branches with a maximum length of zero were collapsed. Measure of branch support is based on decay (Bremer 1988; Donoghue et al. 1992) and bootstrap analyses (Felsenstein 1985). Decay indices were computed using the computer program Autodecay (Eriksson \& Wikstrom 1996). Bootstrap values are based on 500 replicates using strict parsimony in PAUP*. 


\section{RESULTS}

Secondary structure model.-A 503 base pair segment of the $3^{\prime}$ half of $16 \mathrm{~S}$ was obtained for 6 mygalomorph taxa. Figure 1 shows the proposed secondary structure for the mygalomorph Aptostichus atomarius based on the Gutell model. While the mygalomorph model shares substantial physical similarity with the araneomorph and Drosophila models, the underlying RNA sequences vary greatly except in some highly conserved regions (Fig. 1). The location of these conserved regions serve as anchor points for establishing the molecule's overall secondary structure. The structural similarity among the models has been maintained through compensatory changes and by slight shifting of structural regions to accommodate nucleotide substitutions.

Structural evolution in the hypervariable region.-Alignment of $16 \mathrm{~S}$ sequences from the various arachnid taxa sampled revealed a highly variable length of DNA; models of this "hypervariable" region showed marked variation in the size of loops and the length of stems (Fig. 2). Interestingly, bases identified as highly conserved (Buckley et al. 2000) are found adjacent to and even within this region. Evolution in the hypervariable segment of 16S (Fig. 2) reveals an overall trend towards reduction in more advanced arachnids. We will describe this trend moving clockwise through the region (Fig. 2). The models demonstrate extreme variability in loop 1 , which varies in length from 9 nucleotides in Aptostichus to 30 in Ornithodoros (tick). The stem supporting this loop is variable as well, ranging from 3 base pairs in Aptostichus and Heptathela to 11 base pairs in the tick. The connecting region 2 is short in spiders as it is in humans and Drosophila but is longer in Vaejovis (scorpion) and the tick than in spiders. Stem 3, which contains the sequence of four G's common to all organisms, is slightly shorter in the spiders than in the tick or the scorpion. Area 4 consists of approximately the same number of nucleotides in the arachnids sampled; the morphological differences result from different amounts of base pairing. Region 5 is maintained by two sets of bonds, which uphold the structural integrity of the stem but permit sufficient freedom for tertiary interactions. The stem and loop of region 6
Table 2.-Summary of genetic variability within each structural category.

\begin{tabular}{|c|c|c|c|c|}
\hline \multirow[b]{2}{*}{ Structure } & \multicolumn{2}{|c|}{ Mygalomorphs } & \multicolumn{2}{|c|}{ Araneomorphs } \\
\hline & $\begin{array}{c}\text { Number } \\
\text { of } \\
\text { posi- } \\
\text { tions }\end{array}$ & $\begin{array}{l}\text { Per- } \\
\text { cent } \\
\text { vari- } \\
\text { able }\end{array}$ & $\begin{array}{c}\text { Number } \\
\text { of } \\
\text { posi- } \\
\text { tions }\end{array}$ & $\begin{array}{l}\text { Per- } \\
\text { cent } \\
\text { vari- } \\
\text { able }\end{array}$ \\
\hline Stems & 65 & $32 \%$ & 54 & $24 \%$ \\
\hline Inner loops & 62 & $45 \%$ & 62 & $66 \%$ \\
\hline Loops & 103 & $51 \%$ & 99 & $46 \%$ \\
\hline Connecting & 217 & $38 \%$ & 235 & $32 \%$ \\
\hline
\end{tabular}

are most reduced in Aptostichus although the "AUU" sequence in the loop is conserved in all arachnids sampled. The importance of this sequence is supported by Buckley et al. (2000), who found it to be conserved throughout insect taxa. Finally, the length of connector 7 is fairly conserved, ranging from $14 \mathrm{nu}-$ cleotides in Heptathela to 20 in the tick.

Pattern of variation with respect to structure.-Table 2 summarizes the pattern of variation within the $16 \mathrm{~S}$ molecule for mygalomorphs and araneomorphs. A Wilcoxon Rank Sum Test shows that the variability of each structural class $(\mathrm{S}, \mathrm{I}, \mathrm{L}, \mathrm{C})$ is statistically different for both mygalomorphs $(P<0.05)$ and araneomorphs $(P<0.0001)$.

The mean observed variability of the four structural classes differed from both the small (expected $\left.(e)=0.29, \mathrm{X}^{2}=40.34, P<0.005\right)$ and large $\left(e=0.33, \mathrm{X}^{2}=26.93, P<0.005\right)$ random blocks for the araneomorphs. However, the mean variability values for mygalomorphs were not statistically distinct from the random model (small blocks: $e=0.42, \mathrm{X}^{2}=$ 4.49, $P>0.10$; large blocks: $e=0.43, \mathrm{X}^{2}=$ 4.68, $P>0.10)$.

Phylogeny reconstruction.-We consider the phylogenetic signal in this data set to be significant $\left(\mathrm{g}_{1}=-0.55, P<0.01\right)$. A strict parsimony analysis with all positions weighted equally resulted in two equally parsimonious trees (Figs. 3a \& b), 719 steps in length $(\mathrm{CI}=0.61, \mathrm{RI}=0.66)$. Subsequent analyses with loop and inner loop positions first downweighted to 0.20 and then excluded each resulted in one most parsimonious tree with slightly improved CI and RI values (Fig. 4). 


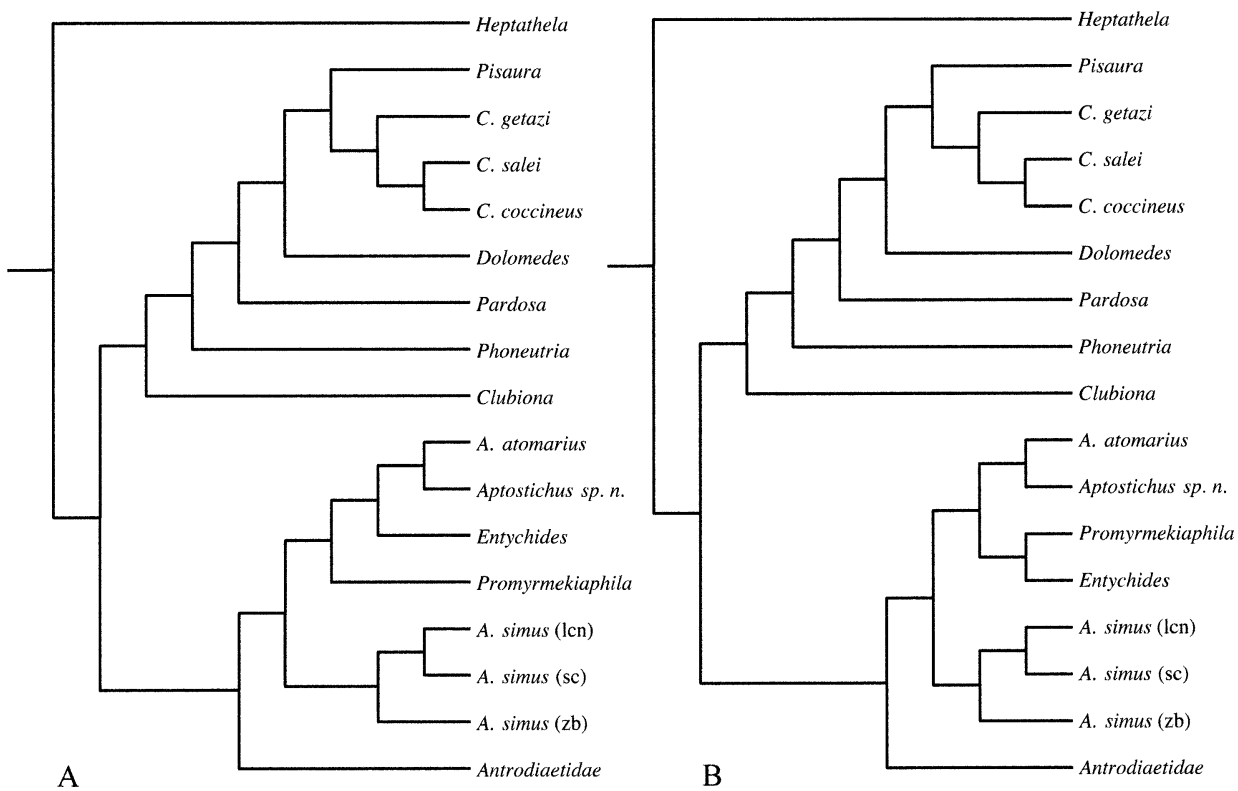

Figures 3 A, B.-Two equally parsimonous trees based on 16S sequences in which all positions are weighted equally, both 719 steps in length $(\mathrm{CI}=0.61, \mathrm{RI}=0.66)$. "C." stands for the genus Cupiennius and "A." for the genus Aptostichus. Locations for A. simus populations are Leo Carillo State Beach, Los Angeles County, CA (lcn), Sycamore Cove Beach, Ventura County CA (sc) and Zuma Beach County Park, Los Angeles County, CA (zb).

\section{DISCUSSION}

Secondary structure.-With the exception of a few hypervariable regions of the molecule, the mygalomorph secondary structure bears close resemblance to those structures proposed for prokaryotes (Gutell 1996; Larsen 1992), insects (Buckley et al. 2000), and araneomorphs (Huber et al. 1993). This supports the findings of Wheeler \& Honeycutt (1988), which demonstrated that Darwinian selection must be operating strongly on these genes to maintain the functional aspects of secondary structure.

The alignment of DNA sequence is computationally difficult (Swofford et al. 1996: Slowinski 1998). Comparison of the mygalomorph model to other arthropod secondary structures facilitated the identification of conserved areas, which were integral to improving the alignment (Buckley et al 2000). Ribosomal RNA sequences add another level of complexity to the problem of sequence alignment because nucleotide site position alignment is determined by secondary structure position homology. Sequence alignments that account for true molecular structural homol- ogy by identifying conserved regions are most likely to reflect true homology and thus correct gene phylogeny, a consideration that may not be reflected in alignment approaches that invoke overall similarity (e.g., Higgins et al. 1996) or concurrent optimizations of alignment and phylogenetic inference (e.g., Wheeler \& Gladstein 1994).

Trends in secondary structure evolution in the hypervariable region.-Examination of the hypervariable region (Fig. 2) suggests a general trend toward the reduction of stems and loops in Araneae. The Aptostichus and Heptathela models exhibit a large deletion in the stem and loop of region 1 (Fig. 2), similar to that observed by Masta (2000) in Habronattus oregonensis (Peckham \& Peckham 1888). The size of region 1 in the scorpion and the tick (39 and 53 nucleotides, respectively) is an intermediate between Drosophila (55 nucleotides) and Aptostichus (15 nucleotides). This suggests a pattern of evolution towards reduction of region 1 , a possible synapomorphy of spiders. However, based on Wheeler \& Hayashi's (1998) chelicerate phylogeny, additional $16 \mathrm{~S}$ sequence data are re- 
quired for at least palpigrades, amblypygids, and schizomids before this can be stated unequivocally. The main exceptions to this reductionary trend are those areas involved in tertiary interactions, such as region 5 and connecting region 7 (Fig. 2). The size of these areas varies little from Drosophila to humans to arachnids.

The extreme variability of region 1 in spiders may be due to its position in the tertiary structure of the fully-formed ribosome. When addressing why a certain segment of a ribosomal subunit is more variable than others, Simon et al. (1994) proposed that it is important to consider the position of the segment in the molecule. Peripheral secondary structure elements tend to be more variable than those on the interior and more frequently undergo modification or elimination. The hypervariabililty of this portion of $16 \mathrm{~S}$ (Fig. 2) suggests that it is probably located on the periphery of the molecule.

Pattern of variation with respect to structure.-Within the Mygalomorphae and Araneomorphae, both the stem (S) and connecting (C) regions exhibited lower variability than the loops (I, L), although this difference was most distinct in the araneomorphs (Table 2). Because stems must base pair to maintain their integrity, changes that disrupt base pairing along the stem will be less likely to occur. Connecting regions are probably more conserved because they have a vital function in maintaining the spatial arrangement of the molecule. Loops are less constrained as changes in their sequence will not interrupt base pairing and at most will threaten tertiary interactions. Additionally, changes in length of the loops will have a small effect on the overall form of the molecule. This disparity in variability between stems and loops is different from what has been observed for other ribosomal RNA molecules. Wheeler \& Honeycutt (1988) found stems to be more variable than loops for 5.8S rRNA, the small nuclear subunit (SSU). They suggest that this was due to the compensatory nature of nucleotide base changes in the stems. Mutations in one base pair would result in a selection pressure for changes in the other, causing stem nucleotide pairs to evolve in concert.

Effects of differential weighting of structural regions. - The results of this study demonstrate the importance of considering $16 \mathrm{~S}$
rRNA secondary structure for phylogenetic reconstruction. Differentially weighting segments of the 16S rRNA based on their structural properties prevents the overemphasis of homoplasic nucleotide positions. This was most evident for the mygalomorph taxa. Down-weighting the variable loops and inner loops improved the phylogenetic tree, which recovered Aptostichus as a monophyletic group (47), a grouping supported by combined analyses of morphological and molecular data (Bond 1999; Bond \& Opell 2002). This ability to fine tune a data set, omitting or differentially weighting hypervariable regions, may allow $16 \mathrm{~S}$ sequence data to be applied more broadly. At the population level, highly variable loops would provide phylogenetic signal while those same loops could be disregarded for comparison of intermediate or very disparate taxa in favor of more conserved stems or connecting regions.

Because this study utilizes only the $3^{\prime}$ half of the 16S, application of our differential weighting scheme may require adjustment when considering the entire molecule. Simon (1991) pointed out that smaller short range stems (terminal stems) vary substantially more than long range stems (supporting stems) and can evolve as rapidly as some loops. Simon (1991) suggested that, if differential weighting were employed, these two types of stems should be distinguished and the rapidly evolving shorter stems should be down-weighted. In the segment of $16 \mathrm{~S}$ used in this study, there were 16 short range stems and only one strand of two long range stems. Therefore, the mean variability for stems could be considered representative of shortrange stems. Perhaps, if the system of differential weighting used in this study were employed on a longer sequence of LSU rRNA, the two stem types would have to be distinguished.

Summary.-The majority of sequence based phylogenetic studies rely solely on DNA sequence alignment algorithms and weighting schemes based on nucleotide compositions. Not surprisingly, this study demonstrates that greater understanding of the processes underlying nucleotide sequence evolution will increase the likelihood of recovering the correct phylogenetic relationships. We show that at very "deep" phylogenetic levels gross secondary structure, the 


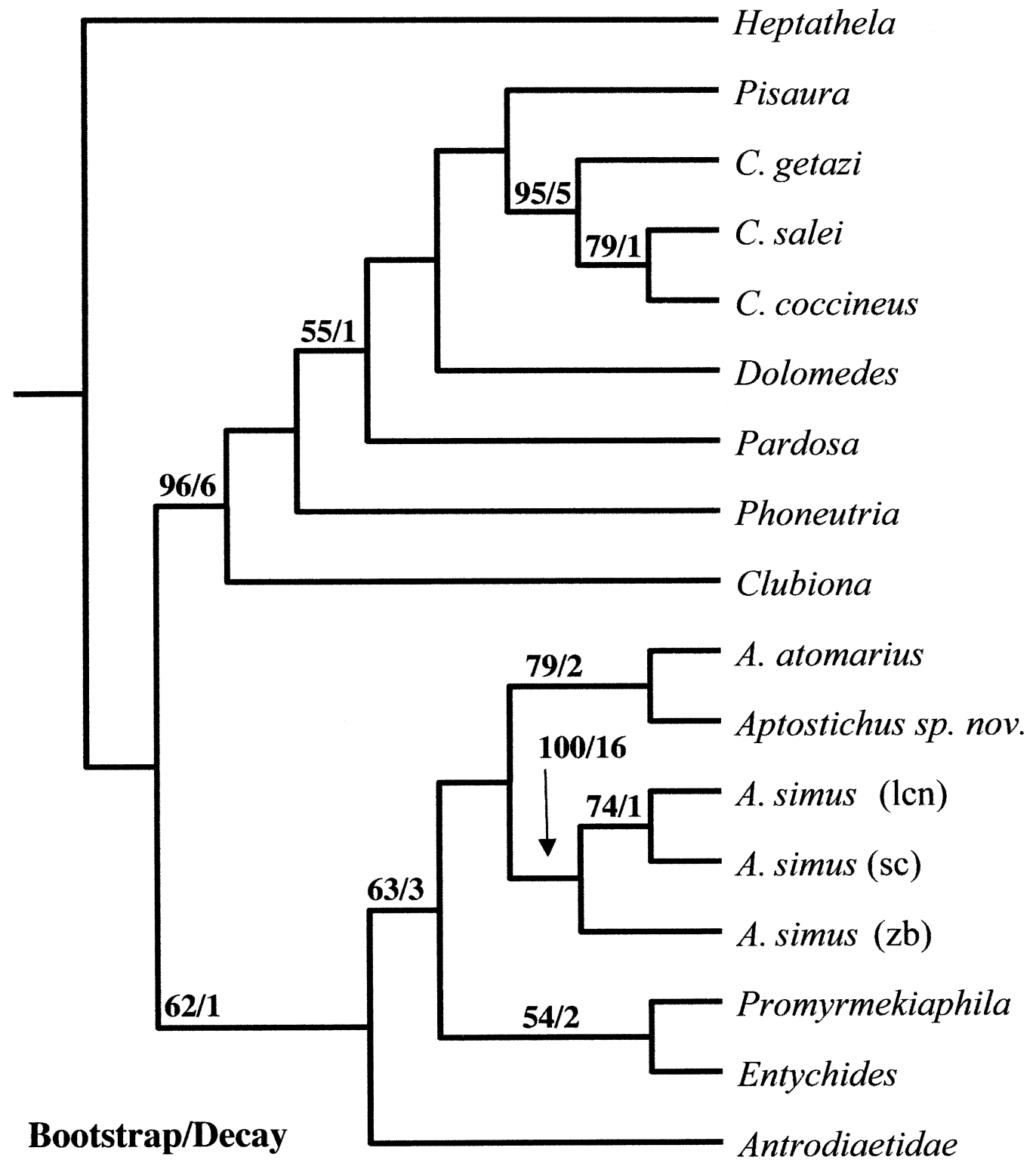

Figure 4.-Tree produced when loop and inner loop positions of $16 \mathrm{~S}$ are down-weighted to 0.20 (520.8 steps, $\mathrm{CI}=0.63, \mathrm{RI}=0.69)$ and when loops and inner loops were excluded $(471$ steps, CI $=0.63$, RI $=0.70$ ). Bootstrap values and decay indices refer to the tree with loops downweighted.

morphology of the molecule, may very well contain phylogenetic information useful in reconstructing arachnid relationships. At more intermediate phylogenetic levels (inter-familial) we show that by down-weighting loop nucleotides phylogenetic signal may be improved. Although the conclusions drawn here may be limited to arachnid studies, the statis- tical approach employed may be useful for studies of secondary structure in other groups.

\section{ACKNOWLEDGMENTS}

This study formed the 1999 undergraduate honor's thesis project for the first author, who wishes to express her gratitude to several members of the Virginia Tech Biology de- 
partment who served on the thesis committee: A. Schultheis, A. L. Buikema, A. C. Hendricks and B. D. Opell. This project was supported by NSF grant DEB 9700814 to J. Bond and B. Opell.

\section{LITERATURE CITED}

Black, W.C. \& J. Piesman. 1994. Phylogeny of hard- and soft-tick taxa (Acari: Ixodida) based on mitochondrial 16S rRNA sequences. Proceedings of the National Academy of Sciences, USA 91:10034-10038.

Bond, J.E., \& B.D. Opell. 2002. Phylogeny and taxonomy of the genera of south-western North American Euctenizinae trapdoor spiders and their relatives (Araneae: Mygalomorphae, Cyrtaucheniidae). Zoological Journal of the Linnean Society 136:487-534.

Bond, J.E., M.C. Hedin, M.A. Ramirez, \& B.D. Opell. 2001. Deep molecular divergence in the absence of morphological and ecological change in the Californian coastal dune endemic trapdoor spider Aptostichus simus. Molecular Ecology 10: 899-910.

Bond, J.E. 1999. Systematics and Evolution of the Trapdoor Spider Genus Aptostichus Simon (Araneae: Euctenizidae). Ph.D. Dissertation, Department of Biology, Virginia Polytechnic Institute and State University.

Bremer, K. 1988. The limits of amino acid sequence data in angiosperm phylogenetic reconstruction. Evolution 42:795-803.

Buckley, T.R., C. Simon, P.K. Flook, \& B. Misof. 2000. Secondary structure and conserved motifs of the frequently sequenced domains IV and $\mathrm{V}$ of the insect mitochondrial large subunit rRNA gene. Insect Molecular Biology 9:565-580.

Clary, D.O. \& D.R. Wolstenholme. 1985. The ribosomal RNA genes of Drosophila mitochondrial DNA. Nucleic Acids Research 13:40294045.

Coddington, J.A. \& H.W. Levi. 1991. Systematics and evolution of spiders (Araneae). Annual Review of Ecology and Systematics 22:565-592.

DeSalle, R., J. Gatesy, W. Wheeler, \& D. Grimaldi. 1992. DNA Sequences from a fossil termite in Oligo-Miocene amber and their phylogenetic implications. Science 257:1933-1936.

Donoghue, M.J., R.G. Olmstead, J.F. Smith, \& J.D. Palmer. 1992. Phylogenetic relationships of Dipscales based on $r b c \mathrm{~L}$ sequences. Annals of the Missouri Botanical Garden 79:333-345.

Eriksson, T. \& N. Wikstrom. 1996. AutoDecay. Stockholm University, Stockholm.

Felsenstein, J.H. 1985. Confidence limits on phylogenies with a molecular clock. Systematic Zoology 34:152-161.

Flook, P.K. \& C.H.F. Rowell. 1995. The effectiveness of mitochondrial rRNA gene sequences for the reconstruction of the phylogeny of an insect order (Orthoptera). Molecular Phylogenetics and Evolution 8:177-192.

Gutell, R.R. 1996. Comparative sequence analysis and the structure of 16 S and 23S rRNA. Pp. 111128. In Ribosomal RNA: Structure, Evolution, Processing, and Function in Protein Biosynthesis. (R. A. Zimmermann \& A. E. Dahlberg, eds.). CRC Press, New York.

Gutell, R.R. \& G.E. Fox. 1988. A compilation of large subunit RNA sequences presented in structural format. Nucleic Acids Research 16:R175R313.

Gutell, R.R., M.N. Schnare \& M.W. Gray. 1993. A compilation of large subunit (23S and 23S-like) ribosomal RNA structures. Nucleic Acids Research 21:3055-3074.

Higgins, D.G., A.J. Bleasby \& R. Fuchs. 1996. Clustal V: Improved software for multiple sequence alignment. Computer Applied Bioscience 8:189-191.

Hillis, D.M. \& J.P. Huelsenbeck. 1992. Signal, noise and reliability in molecular phylogenetic analyses. Journal of Heredity 83:189-195.

Hillis, D.M., B.K. Mable, A. Larson, S.K. Davis \& E.A. Zimmer. 1996. Nucleic Acids IV: Sequencing and cloning. Pp. 321-385. In Molecular Systematics. (D.M. Hillis, C. Moritz \& B.K. Mable, eds.). Sinauer, Sunderland.

Huber, K.C., T.S. Haider, M.W. Miller, B.A Huber, R.J. Schweyen \& F.G. Barth. 1993. DNA sequence data indicates the polyphyly of the family Ctenidae (Araneae). Journal of Arachnology 21: 194-201.

Larsen, N. 1992. Higher order interactions in $23 \mathrm{~S}$ rRNA. Proceedings of the National Academy of Sciences, USA 89:5044-5048.

Masta, S.E. 2000. Mitochrondrial sequence evolution in spiders: Intraspecific variation in tRNAs lacking the $\mathrm{T} \psi \mathrm{C}$ arm. Molecular Biology and Evolution 17:1091-1100.

Simon, C. 1991. Molecular systematics at the species boundary: exploiting conserved and variable regions of the mitochondrial genome via direct sequencing from enzymatically amplified DNA. Pp. 33-71. In Molecular Techniques in Taxonomy. (G.M. Hewitt, A.W.B. Johnston \& J.P.W. Young, eds.). NATO Advanced Studies Institute, H57, Springer, Berlin.

Simon, C., F. Fratl, A. Beckenbach, B. Crespi, H. Liu \& P. Flook. 1994. Evolution, weighting, and phylogenetic utility of mitochondrial gene sequences and a compilation of conserved Polymerase Chain Reaction primers. Annals of the Entomological Society of America 87:651-686.

Slowinski, J.B. 1998. The number of multiple alignments. Molecular Phylogenetics and Evolution 10:264-266.

Swofford, D.L. 1999. PAUP*: Phylogenetic Anal- 
ysis Using Parsimony (and other methods). Sinauer, Sunderland.

Swofford, D.L., G.J. Olsen, P.J. Waddell \& D.M. Hillis. 1996. Phylogenetic inference in molecular systematics. Pp. 407-514. In Molecular Systematics. (D.M. Hillis, C. Moritz \& B.K. Mable, eds.). Sinauer, Sunderland.

Wheeler, W.C. \& D. Gladstein. 1994. MALIGN: A multiple sequence alignment program. Journal of Heredity 85:417.

Wheeler, W.C. \& C.Y. Hayashi. 1998. The phylog- eny of the extant chelicerate orders. Cladistics 14:173-192.

Wheeler, W.C. \& R.L. Honeycutt. 1988. Paired sequence difference in ribosomal RNAs: evolutionary and phylogenetic implications. Molecular Biology and Evolution 5:90-96.

Wolfram, S. 1996. Mathematica. Cambridge University Press, Cambridge.

Manuscript received 13 November 2000, revised 26 February 2002. 